OPEN ACCESS ISSN 25482254 (online) ISSN 20893833 (print)

Edited by:

Cahyo Hasanudin

Reviewed by:

Ari Metalin Ika Puspita

${ }^{*}$ Correspondence:

Ria Fajrin Rizqy Ana

riafajrin88@yahoo.co.id

Received: 6 Agustus 2020 Accepted: 13 Agustus 2020

Published: 20 Agustus 2020

Citation:

Ana RFR (2020) The Influence of the School Literacy Movement through the Utilization of Reading Angles on

Reading Interest of Elementary

School Students.

PEDAGOGIA: Jurnal Pendidikan.

9:2.

doi: 10.21070/pedagogia.v9i2.783

\section{The Influence of the School Literacy Movement through the Utilization of Reading Angles on Reading Interest of Elementary School Students}

\section{Pengaruh Gerakan Literasi Sekolah Melalui Pemanfaatan Sudut Baca Terhadap Minat Baca Siswa Sekolah Dasar}

\author{
Ria Fajrin Rizqy Ana* \\ Program Studi Pendidikan Guru Sekolah Dasar, STKIP PGRI Tulungagung, Indonesia
}

The purpose of this study is to determine the effect of the School Literacy Movement on students' interest in reading at Kendalrejo 01 Public Elementary School. This study used a quantitative approach with an ex post facto method. The instruments used were questionnaires and learning outcomes. The results showed the value of $t_{-}$(count) of 5.498, while t_table is known to be 1.987, then 5.498> 1.987. So it can be concluded that there is a significant effect of the School Literacy Movement on the reading interest of students at SDN Kendalrejo 01 with a coefficient of determination of $25.4 \%$.

Keywords: Literacy, Interest Reading, Elementary School

Tujuan penelitian ini untuk mengetahui pengaruh Gerakan Literasi Sekolah terhadap minat baca siswa SDN Kendalrejo 01. Penelitian ini menggunakan pendekatan kuantitatif dengan metode expost facto. Instrumen yang digunakan yaitu angket dan hasil belajar. Hasil penelitian menunjukan nilai $t_{\text {hitung }}$ sebesar 5,498 , sedangkan $t_{\text {tabel }}$ diketahui sebesar 1,987, maka 5,498 > 1,987. Sehingga dapat disimpulkan bahwa ada pengaruh yang signifikan Gerakan Literasi Sekolah terhadap minat baca siswa SDN Kendalrejo 01dengan koefisien determinasi sebesar 25,4\%.

Keywords: Literacy, Interest Reading, Elementary School

\section{PENDAHULUAN}

Memasuki abad ke-21 diharapkan siswa memiliki kemampuan memahami informasi dan menerapkan berbagai teknik berpikir yang kritis, kreatif pada saat membaca, menulis, dan memecahkan masalah Anjani (2018). Pengetahuan dapat diperoleh melalui berbagai kegiatan, salah satunya dengan membaca. Menurut Musfiroh dan Musfiroh and Listyorini (2016), membaca dipandang sebagai komponen penting untuk kesuksesan sekolah dan siswa membutuhkan kemampuan membaca yang bagus untuk memahami dan mempelajari materi yang beragam di kelas. Membaca merupakan suatu kegiatan yang memiliki banyak yang dapat membuka 
pemikiran dan wawasan akan dunia. Membaca juga mampu membantu menyelesaikan berbagai masalah dalam kehidupannya dengan pengetahuan yang dimiliki. Orang yang senang membaca akan memiliki wawasan baru dan meningkatkan kecerdasannya sehingga lebih mampu menjawab tantangan kehidupan di masa yang akan datang. Selain dapat membuka wawasan, membaca dapat menumbuhkan karakter dan budi pekerti siswa Aini (2018) .

Permasalahan yang terjadi pada siswa SD rata-rata minat atau keinginan untuk membaca sangatlah rendah. Marlina et al. (2017) menyatakan bahwa minat merupakan kecenderungan seseorang untuk memperhatikan suatu kegiatan. Berdasarkan hal tersebut maka jika minat seseorang terhadap kegiatan membaca rendah maka orang tersebut tidak dapat memperhatikan atau fokus dalam melakukan kegiatan membaca. Hal ini dibuktikan berdasarkan Buku Desain Induk Gerakan Literasi Sekolah yang menyatakan bahwa kemampuan literasi masyarakat Indonesia berada di bawah rata-rata Kemendikbud (2016) .

Menurut Pradana (2020) minat baca siswa dipengaruhi beberapa faktor yaitu penyediaan waktu untuk membaca dan pemilihan bacaan yang baik. Pradana (2020) faktor yang mempengaruhi minat baca, antara lain keluarga dan lingkungannya berperan penting dalam menumbuhkan minat baca seseorang. Rofi'uddin et al. (2017) menjelaskan rendahnya minat baca disebabkan oleh mahalnya harga buku dan terbatasnya fasilitas perpustakaan. Oleh karena itu, sekolah harus bisa memfasilitasi sarana yang dapat meningkatkan minat baca siswa yaitu dengan memanfaatkan perpustakaan sekolah. Faktor lain yang menyebabkan rendahnya minat baca siswa antara lain adalah lingkungan belajar yang tidak mendukung, tingginya harga buku yang memberatkan siswa, fasilitas perpustakaan sekolah yang kurang memadai, dan akibat negatif dari perkembangan teknologi yaitu gadget Wirna (2019) .

Permasalahan di atas juga dialami oleh SDN Kendalrejo 01. Menurut pengamatan, rendahnya minat siswa untuk membaca dan berkunjung ke perpustakaan sekolah dikarenakan tidak adanya waktu bagi siswa untuk membaca buku di perpustakaan serta keterbatasan tempat di perpustakaan sekolah. Saat istirahat siswa lebih memilih untuk berada di kelas dan bermain bersama teman dibandingkan dengan berkunjung dan membaca buku ke perpustakaan sekolah. Dalam mengatasi rendahnya minat baca siswa, Kemendikbud menerapkan program Gerakan Literasi Sekolah (GLS). Salah satu kegiatan GLS adalah "membaca buku nonpelajaran selama 15 menit sebelum jam pembelajaran pertama". Kegiatan ini dilakukan untuk menumbuhkan rasa cinta terhadap buku bacaan dan menumbuhkan minat baca siswa. Buku yang dibaca harus memuat nilai-nilai budi pekerti yang disesuaikan dengan tahap perkembangan siswa. Kegiatan GLS ini terbagi menjadi tiga tahap yaitu tahap pembiasaan, pengembangan dan pembelajaran Dewi et al. (2016) .

Kegiatan literasi pada tahap pembiasaan mengenalkan agar siswa terbiasa dan merasa senang dengan buku, untuk itu kegiatan ini diupayakan semenarik mungkin. Tahap kedua kegiatan yang dilakukan etelah siswa berminat membaca dan menyukai kegiatan membaca maka siswa diarahkan untuk meningkatkan kemampuan literasi melalui kegiatan menanggapi cerita atau pun buku pengayaan. Pada tahap pembelajaran, diharapkan kemampuan literasi yang dimiliki diintegrasikan dengan semua mata pelajaran Tarmidzi and Astuti (2020). Dengan demikian siswa diharapkan menjadi pembelajar sepanjang hayat. Pelaksanaan GLS ini juga menyesuaikan dengan kondisi yang dimiliki masing-masing sekolah, ada yang berjalan dengan lancar dan ada pula yang mendapat hambatan pada pelaksanaannya, hal ini terjadi karena kesiapan sekolah berbeda satu dengan yang lainnya. Kesiapan yang diperlukan berupa kesiapan fisik, kesiapan warga sekolah, dan kesiapan sistem pendukung lainnya Dewi et al. (2016). GLS merupakan sebuah program baru yang diterapkan, untuk itu diperlukan adanya penilaian atau evaluasi sejauh mana pengaruh GLS terhadap siswa Susanto (2016) .

Berdasarkan studi pendahuluan melalui wawancara yang dilakukan pada Kepala Sekolah, GLS sudah dilakukan pada tahap pembiasaaan. Kegiatan-kegiatan maupun program GLS yang dijalankan sudah terorganisir dengan baik, di SDN Kendalrejo 01 juga sudah terdapat petugas untuk melayani siswa di perpustakaan. Namun walaupun demikian sarana literasi yang dimiliki masih dalam kategori kurang jika dibandingkan dengan jumlah siswa yang ada di sana. Buku yang dimiliki juga belum bervariasi, jadi siswa akan mudah bosan dengan bahan bacaan yang kurang menarik. Poster atau kampanye budaya membaca juga hanya ada di area tertentu, selain itu kegiatan literasi yang dilakukan kurang melibatkan warga sekolah yang lain. Guru 
masih membiarkan siswa membaca sendiri tanpa memberikan arahan, sehingga siswa yang malas membaca akan tetap malas membaca. Berdasakan hal tersebut maka dapat dinyatakan bahwa kesiapan sekolah tersebut belum maksimal.

Pengembangan budaya literasi untuk meningkatkan minat baca siswa dengan menciptakan dan memanfaatkan sudut baca atau yang biasa disebut dengan perpustakaan kelas. Kemendikbud (2016) menjelaskan tujuan sudut baca yaitu untuk mengenalkan kepada siswa beragam sumber bacaan untuk dimanfaatkan sebagai media, sumber belajar, serta memberikan pengalaman membaca yang menyenangkan. Sudut baca juga sebagai upaya mendekatkan perpustakaan ke siswa. Sudut baca dimanfaatkan secara optimal untuk mendukung keberhasilan proses pembelajaran. Siswa dapat memanfaatkan sudut baca tersebut untuk memperkaya pengetahuannya Kurniawan et al. (2019). Kebaharuan dari penelitian ini GLS baru diterapkan SDN Kendalrejo 01 dan belum pernah ada yang melakukan penelitian ini pada SD di Kecamatan Talun Kabupaten Blitar . Tujuan penelitian untuk mengetahui adakah pengaruh yang signifikan Gerakan Literasi Sekolah terhadap minat baca siswa SDN Kendalrejo 01 Kecamatan Talun Kabupaten Blitar.

\section{METODE}

Penelitian ini menggunakan pendekatan kuantitatif dengan metode expost facto. Subjek penelitiannya adalah siswa SDN Kendalrejo 01 Tahun Pelajaran 2019/2020. Populasi adalah seluruh siswa SDN Kendalrejo 01 yang berjumlah 392 siswa, sedangkan sampel berjumlah 91 siswa yang terdiri dari kelas IV A, IV B, V A dan V B. Teknik sampling yang digunakan h purposive sampling. Penelitian ini dilaksanakan di SDN Kendalrejo 01 yang beralamat di Jalan Raya Kendalrejo No, 23 Desa Kendalrejo Kecamatan Talun Kabupaten. Alasan peneliti memilih SDN Kendalrejo 01 dikarenakan SD tersebut sudah menerapkan GLS.

Instrumen yang digunakan adalah wawancara tidak terstruktur dan angket tertutup. Pengumpulan data GLS diperoleh dari wawancara tidak terstruktur dan angket tertutup. Sub variabel untuk variabel GLS adalah kegiatan pada tahap pembiasaan dengan indikator sebagai berikut; (1)menyediakan bahan bacaan yang beragam, (2) membaca 15 menit sebelum pembelajaran dimulai, (3) menata sarana dan lingkungan kaya literasi, (4)menciptakan lingkungan kaya teks, (5) memilih buku bacaan di SD, (6) Pelibatan publik.

Instrumen untuk variabel minat baca menggunakan angket tertutup dengan indikator sebagai berikut; (1) perasaan senang membaca, (2) memiliki keinginan yang kuat untuk membaca, (3) keingintahuan akan isi bacaan, (4) kesadaran akan pentingnya membaca, (5) menyukai berbagai bahan bacaan, (6) perasaan puas setelah membaca. Skala yang digunakan adalah skala Likert dengan 4 pilihan jawaban. Soal yang diberikan berupa soal positif dan soal negatif. Pilihan jawaban pada soal positif adalah (a) selalu, (b) sering, (c) jarang, (d) tidak pernah, sedangkan untuk pilihan jawaban pada soal negatif adalah (a) tidak pernah, (b) jarang, (c)sering, (d) selalu. Pedoman penskorannya jika menjawab (a) skor 4, (b) skor 3, (c) skor 2, dan (d) skor 1.

Teknik analisis data yang digunakan uji instrumen berupa uji validitas menggunakan rumus korelasi Pearson Product Moment dan uji reliabilitas menggunakan Cronbach's Alpha. Sedangkan uji prasyarat analisis yang digunakan adalah uji normalitas menggunakan metode Kolmogorov-Smirnov, dan uji homogenitas menggunakan Levene Statistic. Untuk mengetahui pengaruh variabel X (GLS) terhadap variabel Y (minat baca) menggunakan analisis regresi linier sederhana dengan taraf signifikansi 0,05.

\section{HASIL DAN PEMBAHASAN}

Data variabel minat baca didapatkan dari angket yang diberikan kepada siswa. Angket yang diberikan terdiri dari 22 soal dengan 4 pilihan jawaban. Data angket tentang minat baca disajikan dalam bentuk tabel dan diagram distribusi frekuensi minat baca (Y). Rinciannya adalah sebagai berikut.

[Table 1 about here.] 
Penjelasan tambahan untuk variabel minat baca siswa SDN Kendalrejo 01, data juga disajikan dalam bentuk diagram sebagai berikut.

[Figure 1 about here.]

Berdasarkan tabel 1 dan diagram 1dapat diketahui bahwa minat baca siswa SDN Kendalrejo 01 berada pada kategori sangat tinggi terdapat 8 siswa, kategori tinggi terdapat 41 siswa, pada kategori sedang terdapat 40 siswa, dan pada kategori rendah terdapat 2 siswa, sedangkan pada kategori sangat rendah terdapat 0 siswa. Sehingga dapat disimpulkan bahwa minat baca siswa SDN Kendalrejo 01 berada pada kategori tinggi. Data tentang Gerakan Literasi Sekolah diperoleh dari wawancara yang dilakukan kepada Kepala Sekolah dan Petugas Perpustakaan dan angket yang diberikan kepada siswa. Jenis wawancara yang digunakan adalah wawancara tidak terstruktur, sehingga tidak menggunakan pedoman wawancara, sedangkan angket yang diberikan terdiri dari 18 soal dengan 4 alternatif jawaban.

Berdasarkan hasil wawancara yang dilakukan menunjukkan bahwa SDN Kendalrejo 01 telah melaksanakan program GLS ini sejak tahun 2018. Program GLS yang dilaksanakan adalah: (a) Literasi Perpustakaan, (b) Literasi Kelas (Pojok Literasi), (c) Perpustakaan Keliling, (d) Reading Day dari penerbit buku, dan (e) Kunjungan Rumah Pintar. Bahan bacaan yang tersedia baik fiksi maupun non fiksi sejumlah 963eks. Program yang direncanakan sudah dijalankan secara rutin, namun masih terdapat beberapa kendala yakni minimnya sarana dan prasarana yang dimiliki pihak sekolah, seperti belum memiliki gedung perpustakaan yang mandiri, minimnya bahan bacaan, dan kurang memanfaatkan area sekolah sebagai area literasi. Walaupun demikian terdapat juga faktor pendukung berjalannya program GLS, yaitu adanya program penggerakan minat baca yang sudah secara rutin dilakukan, dan siswa antusias mengikuti berbagai program GLS yang ada.

Data angket dari siswa disajikan dalam tabel dan diagram distribusi frekuensi Gerakan Literasi Sekolah (X) sebagai berikut.

[Table 2 about here.]

Berikut adalah grafik Gerakan Literasi Sekolah (GLS) sebagai data tambahan tentang pelaksanaan GLS pada siswa SDN Kendalrejo 01

[Figure 2 about here.]

Berdasarkan tabel 2 dan diagram 2menunjukkan bahwa Gerakan Literasi Sekolah (GLS) di SDN Kendalrejo 01 dalam kategori sangat baik terdapat 11 siswa, pada kategori baik terdapat 60 siswa, kategori cukup ada 20 siswa, dan pada kategori kurang dan sangat kurang tidak terdapat siswa atau 0. Sehingga dapat disimpulkan bahwa GLS berada pada kategori baik. Analisis data yang digunakan pada penelitian ini adalah analisis regresi sederhana, sebelum melakukan analisis regresi maka harus melakukan uji prasyarat analisis, yakni uji normalitas dan uji homogenitas. Uji prasyarat analisis sudah dilakukan dengan hasil yang menunjukkan bahwa data berdistribusi normal, dan sampel berasal dari varian yang sama. Analisis regresi sederhana digunakan untuk mengetahui pengaruh Gerakan Literasi Sekolah (GLS) terhadap minat baca siswa. Berikut adalah hasil analisis regresi sederhana.

[Table 3 about here.]

Diketahui bahwa $\mathrm{t}_{\text {hitung }}(5,498)>\mathrm{t}_{\text {tabel }}(1,987)$, maka dapat disimpulkan bahwa ada pengaruh yang signifikan antara Gerakan Literasi Sekolah (GLS) terhadap minat baca siswa. Hasil uji hipotesis menunjukkan nilai signifikansi 0,000 yang berarti $<0,05$, maka dapat dinyatakan bahwa ada pengaruh yang signifikan Gerakan Literasi Sekolah terhadap minat baca siswa SDN Kendalrejo 01 atau Ha diterima. Persamaan regresinya adalah $\mathrm{Y}=21,103+0,691 \mathrm{X}$. Berikut gambar grafik persamaan regresi.

[Figure 3 about here.]

Berdasarkan garis linier sederhana di atas dapat disimpulkan, yaitu jika variabel Gerakan Literasi Sekolah (X) mengalami kenaikan atau penambahan satu satuan maka variabel minat baca (Y) akan mengalami kenaikan sebesar 0,691, dengan asumsi bahwa variabel lainnya konstan atau tetap. 


\section{Pengaruh GLS Melalui Pemanfaatan Sudut Baca Terhadap Minat Baca Siswa SDN Kendalrejo 01}

Hasil penelitian ini menunjukkan bahwa ada pengaruh yang signifikan Gerakan Literasi Sekolah (GLS) terhadap minat baca siswa. GLS pada penelitian ini sesuai dengan teori yang dinyatakan oleh Dewi et al. (2016) yakni upaya yang menyeluruh guna menjadikan sekolah sebagai tempat pembelajaran yang menjadikan warganya pembelajar sepanjang hayat dengan melibatkan publik. GLS diharapkan menjadi jawaban atas berbagai permasalahan yang terjadi pada sekarang, dengan literasi diharapkan siswa mampu mencari, mengolah, dan memanfaat informasi yang berguna untuk kehidupannya. Program GLS merupakan program yang menuntut pelibatan aktif setiap elemen pendidikan Abidin et al. (2018). Untuk itu maka GLS dilaksanakan dengan memperhatikan karakteristik sekolah agar mampu memberikan perlakuan atau program yang menyeluruh dari segala aspek (whole school approach) Kemendikbud (2016)

GLS diharapkan mampu menjadikan siswa mampu untuk mengembangkan kemampuan literasinya yang diawali dengan tumbuhnya minat baca. Hal ini sesuai dengan teori yang dikemukakan oleh Gagne bahwa minat dapat ditimbulkan melalui pola atau pembiasaan Susanto (2016) . GLS merupakan salah satu program pembiasaan untuk menumbuhkan minat baca. Menurut Rahim (2018) minat baca adalah kemauan yang kuat dari dalam diri seseorang disertai usaha untuk membaca. Minat baca timbul dari dalam diri seseorang tanpa ada paksaan dari orang lain, namun minat dapat ditumbuhkan melalui pembinaan atau pembiasaan. Menurut Hapsari and Rachmawati (2018) minat merupakan pendorong utama sesorang untuk melakukan suatu kegiatan, sama halnya dengan membaca. Orang yang senang membaca berarti memiliki minat yang tinggi terhadap kegiatan membaca. Hasil penelitian ini juga mendukung hasil penelitian yang sebelumnya sudah dilakukan oleh Aini (2018) dengan judul "Pengaruh Budaya Literasi dalam Mengembangkan Kecerdasan Kewarganegaraan”. Hasil penelitian menunjukkan bahwa budaya membaca dapat mengembangkan kompetensi kecerdasan kewarganegaraan siswa. Aspek yang paling berkembang secara signifikan dari kecerdasan kewarganegaraan adalah kecerdasan intelektual, kecerdasan emosional, dan kecerdasan moral. Artinya dengan adanya budaya membaca selain dapat membentuk karakter dan budi pekerti, dapat pula meningkatkan kecerdasan kewarganegaraan.

Penelitian yang sama juga dilakukan oleh Batubara and Ariani (2018) dengan judul "Implementasi Program Gerakan Literasi Sekolah di Sekolah Dasar Negeri Gugus Sungai Miai Banjarmasin". Hasil penelitian menunjukkan bahwa pelaksanaan program gerakan literasi sekolah di SDN Gugus Sungai Miai Banjarmasin berada pada tahap pembiasaan. Upaya-upaya yang dilakukan sekolah dalam melaksanakan program gerakan literasi sekolah adalah: (1) menambah buku pengayaan, (2) mendekatkan buku ke peserta didik dengan cara membuat area baca dan lingkungan yang kaya akan teks, (3) melaksanakan berbagai bentuk kegiatan literasi, dan (4) melibatkan publik dalam pelaksanaan gerakan literasi. Adapun kendala yang dihadapi sekolah dalam pelaksanaan GLS adalalah: (1) rendahnya kesadaran guru, (2) buku pengayaan yang sesuai dengan kebutuhan anak sulit ditemukan, (3) guru malas membaca, (4) guru tidak memahami penerapan gerakan literasi, dan (5) sekolah kekurangan dana. Masalah yang dialami dalam pelaksanaan program GLS ini hampir sama, dan diharapkan pihak sekolah mampu memberi jalan keluar terbaik agar pelaksanaan dan manfaat dari GLS bisa maksimal.

Berdasarkan hal di atas menunjukkan bahwa selain menumbuhkan minat baca, ternyata budaya literasi yang diwujudkan dalam program GLS mampu memberikan efek yang cukup signifikan terhadap siswa, baik berupa kecerdasan intelektual, kecerdasan emosional, maupun moral. Melalui GLS siswa diharapkan mampu menjadi pembelajar sepanjang hayat. Untuk itu perlu dilaksanakan berbagai peningkatan program yang berbasis literasi yang ditujukan kepada siswa.

\section{KESIMPULAN}

Berdasarkan analisis data hasil penelitian dan pembahasan dapat disimpulkan bahwa terdapat pengaruh yang signifikan Gerakan Literasi Sekolah terhadap minat baca siswa SDN Kendalrejo 01. Persamaan regresinya yakni, $Y=21,103+0,691 X$, hal ini menunjukkan bahwa jika ter- 
jadi penambahan satu satuan pada variabel Gerakan Literasi Sekolah maka variabel minat baca akan mengalami kenaikan sebesar 0,691. Sedangkan koefisien determinasi sebesar 0,254 atau $25,4 \%$ yang artinya minat baca siswa dipengaruhi oleh Gerakan Literasi Sekolah sebesar 25,4\% sedangkan 74,6\% dipengaruhi oleh faktor lain yang tidak diteliti dalam penelitian ini.

\section{UCAPAN TERIMAKASIH}

Terima kasih peneliti sampaikan kepada STKIP PGRI Tulungagung yang telah membiayai penelitian ini. Peneliti juga mengucapkan terima kasih yang sebanyak-banyaknya pada pihak yang telah membantu peneliti dalam melaksanakan kegiatan penelitian, yaitu Ibu Kepala Sekolah, Bapak/Ibu Guru, dan seluruh siswa SDN Kendalrejo 01. Tidak lupa peneliti juga menyampaikan terimak kasih kepada teman-teman Prodi PGSD STKIP PGRI Tulungagung yang selalu memberikan motivasi, bantuan sehingga peneliti dapat menyelesaikan penelitian ini.

\section{REFERENCES}

Abidin, Y., Mulyati, T., and Yunansah, H. (2018). Pembelajaran Literasi (Jakarta: PT Bumi Aksara).

Aini, D. N. (2018). Pengaruh Budaya Literasi dalam Mengembangkan Kecerdasan Kewarganegaraan. BIORMATIKA JURNAL ILMIAH FAKULTAS KEGURUAN DAN ILMU PENDIDIKAN 4, 1-10.

Anjani (2018). Pengaruhimplementasigerakanliterasi Sekolah Terhadap Minat Bacadankemampuan Membaca Pemahamansiswakelas Vsd Gugusiikutautara. Journal Pendidikan Dasar Indonesia 3, 15-29.

Batubara, H. H. and Ariani, D. N. (2018). IMPLEMENTASI PROGRAM GERAKAN LITERASI SEKOLAH DI SEKOLAH DASAR NEGERI GUGUS SUNGAI MIAI BANJARMASIN. Jurnal Pendidikan Sekolah Dasar 4, 15-23. doi http://dx.doi.org/10.30870/jpsd.v4i1.2965.

Dewi, U. F., Sufyadi, S., Anggraini, L., Waluyo, Dewayani, S., Muldian, W., et al. (2016). Panduan Gerakan Literas di Sekolah Dasar (Jakarta: Direktorat Jenderal Pendidikan Dasar dan Menengah Kementrian Pendidikan dan Kebudayaan).

Hapsari, S. and Rachmawati, L. (2018). Pengaruh Minat Baca dan Penggunaan Gadget terhadap Hasil Belajar Ekonomi Peserta Didik Kelas X IPS MA Al-Hidayah Bangkalan. Jurnal Pendidikan Ekonomi 6, 17-22.

Kemendikbud (2016). Desain Induk Gerakan Literasi Sekolah (Jakarta: Direktorat Jenderal Pendidikan Dasar dan Menengah Kementrian Pendidikan dan Kebudayaan).

Kurniawan, A. R., Destrinelli, Hayati, S., Rahmad, R., Riskayanti, J., Wasena, I. S., et al. (2019). Peranan Pojok Baca Dalam Menumbuhkan Minat Baca Siswa Sekolah Dasar. Jurnal Inovasi Pendidikan dan Pembelajaran Sekolah Dasar 3, 48-57. doi: https://doi.org/10.24036/jippsd. v3i2.107562.

Marlina, L., Caska, and Mahdum (2017). Hubungan Minat Baca dan Motivasi Belajar dengan Hasil Belajar Ekonomi Siswa Kelas XI IPS SMAN 10 Pekanbaru. Pekbis Jurnal 9 , 33-47.

Musfiroh, T. and Listyorini, B. (2016). KONSTRUK KOMPETENSI LITERASI UNTUK SISWA SEKOLAH DASAR.
LITERA 15. doi: 10.21831/ltr.v15i1.9751.

Pradana, F. A. P. (2020). Pengaruh Budaya Literasi Sekolah Melalui Pemanfaatan Sudut Baca Terhadap Minat Membaca Siswa Di Sekolah Dasar. Jurnal Pendidikan dan Konseling 1, 94-104. doi: https://doi.org/10.31004/jpdk.v1i2. 599.

Rahim, F. (2018). Pengajaran Membaca di Sekolah Dasar (Jakarta: PT Bumi Aksara), 1-180.

Rofi'uddin, M. A., Hermintoyo, , and and (2017). PENGARUH POJOK BACA TERHADAP PENINGKATAN MINAT BACA SISWA DI SMP NEGERI 3 PATI. Jurnal Ilmu Perpustakaan 6, 281-290.

Susanto, A. (2016). Teori Belajar \& Pembelajaran di Sekolah Dasar. In Peraturan Menteri Pendidikan dan Kebudayaan RI Nomor 23 Tahun 2015 tentang Penumbuhan Budi Pekerti, ed. and others (Jakarta: Prenadamedia Group.).

Tarmidzi and Astuti, W. (2020). Pengaruh Kegiatan Literasi Terhadap Minat Baca Siswa di Sekolah Dasar. Jurnal Ilmu Pendidikan Dasar 3, 40-51. doi: http://dx.doi.org/10. 33603/caruban.v3i1.3361.

Wirna (2019). Pengelolaan Sudut Baca di Lingkungan Sekolah dalam Menumbuhkan Budaya Literasi dada Siswa MTsN 1 Kota Makassar. http://repositori.uin-alauddin.ac.id/ $15222 /$.

Conflict of Interest Statement: The author declare that the research was conducted in the absence of any commercial or financial relationships that could be construed as a potential conflict of interest.

Copyright (c) 2020 Ana. This is an open-access article distributed under the terms of the Creative Commons Attribution License (CC BY). The use, distribution or reproduction in other forums is permitted, provided the original author(s) and the copyright owner(s) are credited and that the original publication in this journal is cited, in accordance with accepted academic practice. No use, distribution or reproduction is permitted which does not comply with these terms. 


\section{LIST OF TABLES}

1 DistribusiFrekuensi Minat Baca . . . . . . . . . . . . . . . . . 218

2 DistribusiFrekuensi Gerakan Literasi Sekolah . . . . . . . . . . . . . . . 219

3 Perhitungan Regresi LinierSederhana Perhitungan Regresi Linier Sederhana

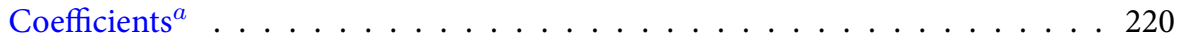


TABLE 1 | DistribusiFrekuensi Minat Baca

\begin{tabular}{lllll}
\hline No & Kategori & Rentang Nilai & Frekuensi & Persentase \\
1 & Sangat Tinggi & $72-89$ & 8 & $9 \%$ \\
2 & Tinggi & $54-71$ & 41 & $45 \%$ \\
3 & Sedang & $36-53$ & 40 & $44 \%$ \\
4 & Rendah & $18-35$ & 2 & $2 \%$ \\
5 & Sangat Rendah & $0-17$ & 0 & $0 \%$ \\
Jumlah & & 91 & $100 \%$ \\
\hline
\end{tabular}


TABLE 2 | DistribusiFrekuensi Gerakan Literasi Sekolah

\begin{tabular}{lllll}
\hline No & Kategori & Rentang Nilai & Frekuensi & Persentase \\
1 & Sangat Baik & $60-74$ & 11 & $12 \%$ \\
2 & Baik & $45-59$ & 60 & $66 \%$ \\
3 & Cukup & $30-44$ & 20 & $22 \%$ \\
4 & Kurang & $15-29$ & 0 & $0 \%$ \\
5 & Sangat Kurang & $0-14$ & 0 & $0 \%$ \\
Jumlah & & 91 & $100 \%$ \\
\hline
\end{tabular}


TABLE 3 | Perhitungan Regresi LinierSederhana Perhitungan Regresi Linier Sederhana Coefficients $^{a}$

\begin{tabular}{|c|c|c|c|c|c|c|}
\hline \multicolumn{7}{|c|}{ Coefficientsa } \\
\hline \multirow{2}{*}{\multicolumn{2}{|c|}{ Model }} & \multicolumn{2}{|c|}{$\begin{array}{l}\text { Unstandardized } \\
\text { Coefficients }\end{array}$} & Standardized Coefficients & \multirow[t]{2}{*}{$\mathrm{t}$} & \multirow[t]{2}{*}{ Sig. } \\
\hline & & & Std. Error & Beta & & \\
\hline \multirow{2}{*}{1} & (Constant) & 21,103 & 6,378 & & 3,309 & ,001 \\
\hline & GLS & ,691 & ,126 &, 504 & 5,498 & ,000 \\
\hline \multicolumn{7}{|c|}{ a. Dependent Variable: Minat Baca } \\
\hline
\end{tabular}




\section{LIST OF FIGURES}

1 Distribusi FrekuensiMinat Baca . . . . . . . . . . . . . . . . . 222

2 Distribusi FrekuensiGerakan Literasi Sekolah . . . . . . . . . . . . . 223

3 Grafik Persamaan Regresi . . . . . . . . . . . . . . . . . . . . . 224 


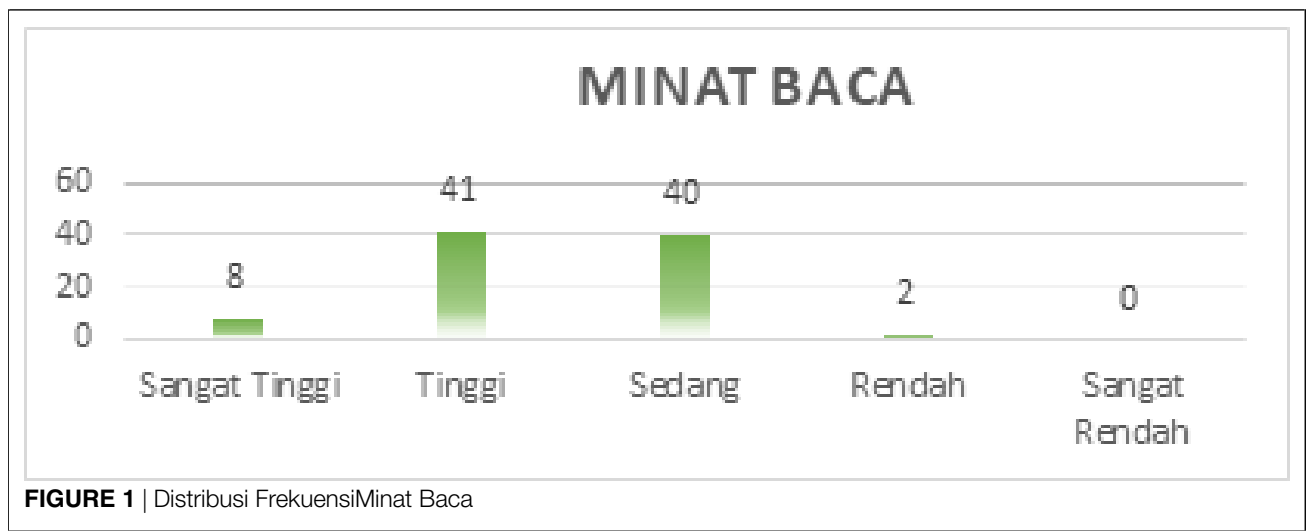




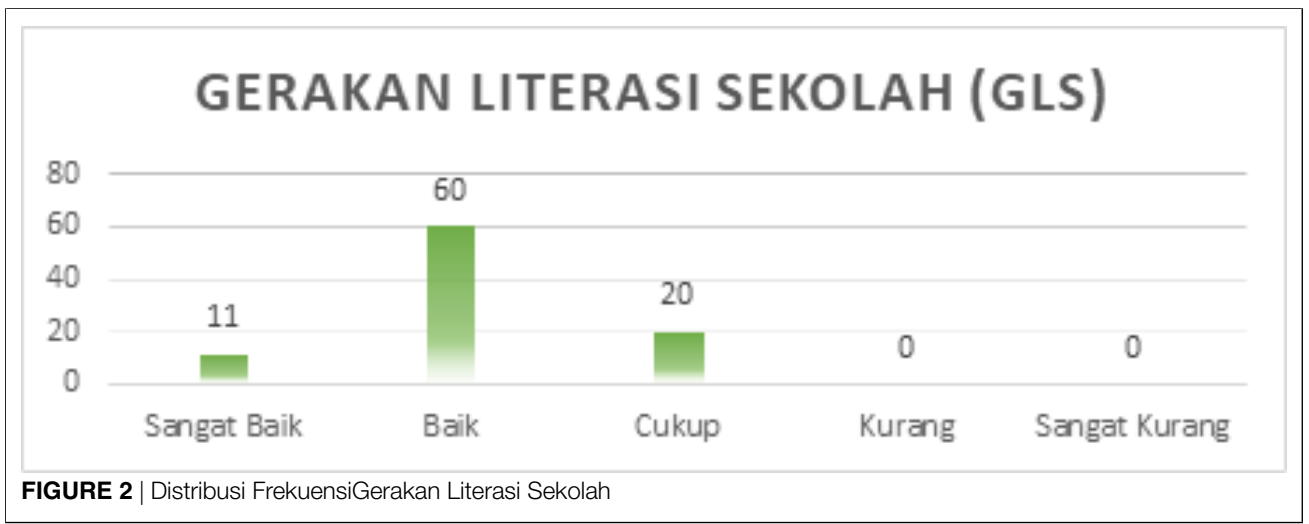




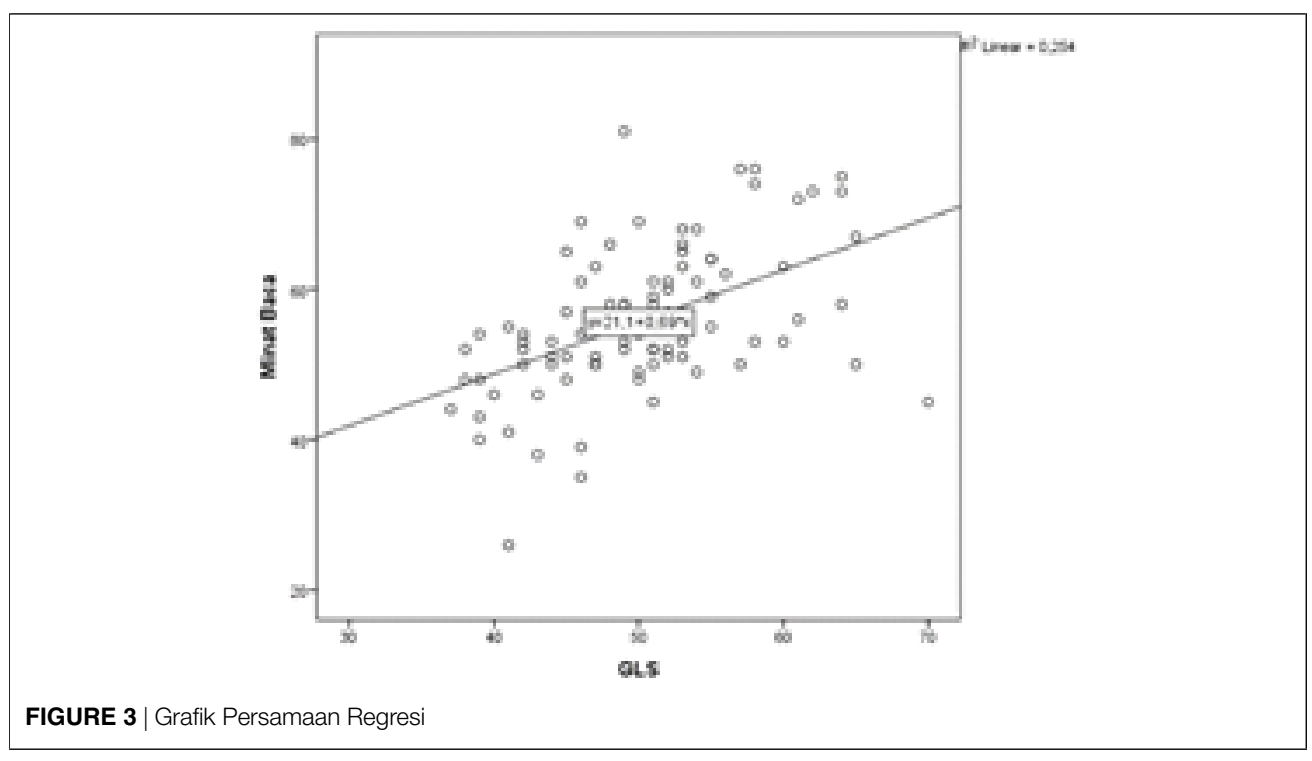

